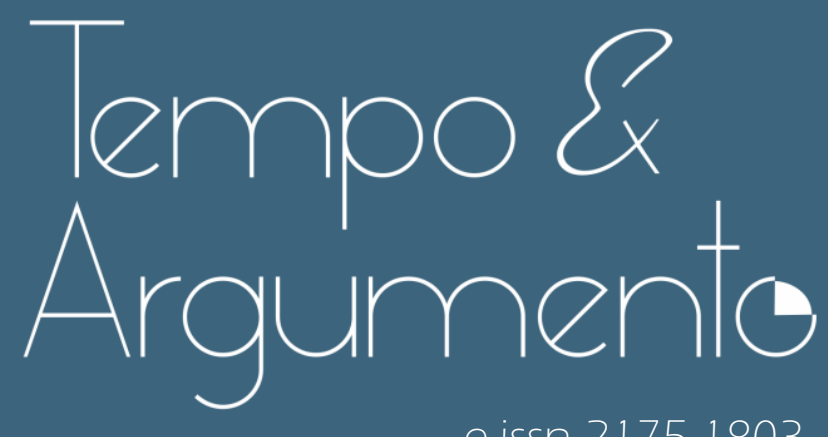

e-issn 2175-1803

\title{
Mulheres e(m) quadrinhos: caminhos e perspectivas historiográficas
}

- Ivan Lima Gomes

Doutor em História pela Universidade Federal Fluminense (UFF).

Professor do Programa de Pós-Graduação em História da

Universidade Federal de Goiás (UFG).

Goiânia, GO - BRASIL

lattes.cnpq.br/0575667160905102

igomes2@gmail.com

(iD) orcid.org/0000-0001-7873-8484

Para citar este artigo:

GOMES, Ivan Lima. Mulheres e(m) quadrinhos: caminhos e perspectivas historiográficas. Tempo e Argumento, Florianópolis, v. 12, n. 31 , e0 107. set./dez. 2020.

doi http://dx.doi.org/10.5965/2175180312312020e0 107

Recebido: 18/04/2020

Aprovado: 25/05/2020 


\title{
Mulheres e $(\mathrm{m})$ quadrinhos: caminhos e perspectivas historiográficas
}

\begin{abstract}
Resumo
Nos primeiros anos do século XXI, observa-se a força do movimento feminista e de reinvindicações políticas comprometidas em estabelecer o protagonismo das mulheres na esfera pública. No mesmo contexto, ocorre um aumento no interesse sobre as histórias em quadrinhos ( $\mathrm{HQs}$ ) enquanto linguagem dotada de procedimentos bastante específicos, em que a narrativa visual possibilita representar outras perspectivas sobre a experiência humana no tempo. Não por acaso, as HQs permitem dar visibilidade e abordar de maneira única as lutas feministas do tempo presente, o que se expressa, por sua vez, numa crescente produção acadêmica que busca rever o lugar das mulheres no mundo das HQs. O presente artigo é uma aproximação sobre este vasto corpus bibliográfico, focando a análise em alguns trabalhos importantes dedicados a investigar a atuação das mulheres nas HQs, incluindo uma análise de pesquisas acadêmicas sobre HQs desenvolvidas mais recentemente no Brasil. A conclusão sinaliza para algumas das possibilidades de investigação futura, destacando as especificidades da linguagem das HQs para narrar e representar graficamente a condição feminina no mundo contemporâneo.
\end{abstract}

Palavras-chave: Histórias em Quadrinhos. História das Mulheres. Feminismo.

\section{Women in/and comics: bibliographic notes}

\begin{abstract}
In the early years of the 21st century, we can see the strength of the feminist movement and political demands committed on establishing the role of women in public sphere. In the same context, there is also an increased interest in comics as a language endowed with very specific procedures, where the visual narrative makes it possible to represent other perspectives on human experience in time. It is not by chance that comics allow visibility and represents in a unique way the feminist struggles of the time, which is expressed, in turn, in a growing academic production that seeks to review the place of women in the comics art world. This article is an approximation to this vast bibliographic corpus, focusing the analysis on some important works dedicated to investigate the place of women in comics, including an analysis on recent Brazilian comics scholarship. The conclusion points to some of the possibilities for future research, highlighting the specificities of the language of comics to narrate and graphically represent the female condition in the contemporary world.
\end{abstract}

Keywords: Comics. Women History. Feminism. 


\section{Introdução: HQs e feminismo no tempo presente}

A despeito de uma longa trajetória na história contemporânea, o debate feminista consolida-se, nas primeiras décadas do século XXI, como uma das bandeiras identitárias e políticas das mais importantes para a mobilização social e a luta pelo fim de desigualdades históricas. Sem silenciar as reivindicações legítimas de grupos e movimentos subalternizados e de histórias igualmente relevantes, as demandas associadas ao lugar das mulheres num mundo de relações mediadas por tecnologia, precarização do trabalho e certo esgotamento da política democrática representativa mostram-se, hoje, incontornáveis.

Se, para alguns setores conservadores, esse cenário parece assombrar e leva à paralisia ou à busca por opções que oferecem verdades em troca do rebaixamento da dignidade humana, para as feministas da chamada "quarta onda" revelou-se uma oportunidade para trazer visibilidade às suas bandeiras, numa amplitude inédita até então. Termos e expressões associados a elas ganham o debate público, cada vez mais pautado por iniciativas críticas ao machismo historicamente enraizado entre nós.

Para pensar em exemplos caros à realidade brasileira, lembremos que as primeiras grandes manifestações progressistas ligadas às eleições de 2018 originaram-se da campanha \#elenão. A hashtag era uma recusa ao então candidato à presidência Jair Bolsonaro, que fez uma carreira política às custas de afirmações de ódio e misoginia, e levou milhares de mulheres às ruas em setembro daquele ano. A despeito do silêncio da imprensa televisiva, a mobilização espalhou-se pelas redes sociais e chegou às ruas; a imprensa noticiou o ato como o "maior protesto liderado por mulheres no Brasil" (JIMÉNEZ, 2018).

Verdadeiro campo minado da vida pública no tempo presente, as tensões das redes sociais permitiram que expressões como "visibilidade" e "representatividade" assumissem nova força. E as histórias em quadrinhos (HQs)

\footnotetext{
A designação "quarta onda" ainda não é consensual entre estudiosos de feminismo. Porém, para fins deste artigo, ela é útil por demarcar as especificidades das lutas feministas no Tempo Presente, marcadas pela forte mobilização, que vai do digital às ruas, de combate a expressões machistas de poder e violência que ainda persistem nos dias de hoje, sintetizadas em expressões como "cultura do estupro" e "feminicídio" - expressões estas que, cada vez mais e merecidamente, ganham legitimidade e solidez no debate público, o que dá relevo à própria ideia de "quarta onda do feminismo" (PEREZ; RICOLDI, 2019, p. 01-22).
} 
ingressaram ativamente nesse debate. Misto de imagem e texto, as HQs sempre escaparam das delimitações simples. Como defini-las? São literatura ou arte visual? Devem ser lidas por crianças ou adultos? São leitura para meninos ou meninas? Trata-se de uma arte que hibridiza imagens, textos e outros recursos de mídia, cujo caráter transmidiático, aberto a influências e em constante transformação permite ressignificar a palavra inglesa utilizada para defini-las: de comics, podem ser vistas como co-mix².

Nesse sentido, elas dialogam bastante com a emergência dos estudos em história das mulheres, tal como percebido por Joan Scott. Interessa-nos aqui apontar, a partir de Scott, a urgência de perceber a especificidade dos problemas que uma análise das mulheres impõe ao historiador não só enquanto objeto histórico a ser acrescentado ao seu leque temático, mas também como elemento-chave que problematiza e coloca em xeque o próprio estatuto epistemológico que norteia a escrita da História - marcada por, entre outros aspectos, um sujeito e uma escrita que se pretendem universais (SCOTT, 1995, p. 71-99). Isso para não falar das motivações iniciais associadas às lutas por direitos civis nos anos 1970, à institucionalização acadêmica e seus dilemas com a militância e à constatação das "diferenças dentro da diferença" a partir dos anos 1980, e que levou às atuais preocupações que giram em torno de uma noção como gênero (SCOTT, 1992, p. 75-85).

Por outro lado, é essa mesma condição híbrida que lhes permite transitar por formatos tão diversos - da tira de jornal à webcomic, passando pela revista ou livro - e tocar em temas difíceis com rara sensibilidade. O brutal assassinato da vereadora Marielle Franco (PSOL) e de seu motorista, Anderson Gomes, chocou a todos, dentro e fora do Brasil - assim como é estarrecedor saber que, passados mais de dois anos, ainda não sabemos quem foram os mandantes dos assassinatos. Rapidamente, seu rosto tornou-se uma mídia a representar todo o absurdo da política recente brasileira, marcada pela Operação Lava-Jato e seu desdobramento moral, o lavajatismo; a incontrolável violência urbana, sob a cumplicidade de muitos agentes da lei, através da atuação em milícias; e da ascensão de uma candidatura que tinha na intolerância e na dissolução do outro

${ }^{2}$ É o que defende W. J. T. Mitchell (2014), inspirando-se em expressão cunhada originalmente pelo artista de HQs, Art Spiegelman. 
as suas bandeiras políticas. Marielle Franco tornou-se uma bandeira de luta, simbolizando o silenciamento histórico e recorrente de outras identidades: mulher, negra, homossexual, politizada e crítica das injustiças. As HQs responderam imediatamente e contribuíram para dar voz e rosto a Marielle Franco, ajudando a torná-la uma referência internacional em defesa de uma sociedade mais justa, vide o caso de Per Marielle Cattiva Ragazza, HQ sobre a vereadora e produzida pelos italianos Assia Petricelli e Sergio Riccardi e originalmente publicada no jornal italiano Il Manifesto em 30 de março de 2018.

Uma HQ que dá corpo e voz a Marielle Franco atua, pois, no campo das sensibilidades e, desde uma perspectiva histórica, possibilita "construir imagens do outro, dar forma ao imaginário social", conforme defende Alain Corbin (2005, p. 19). O outro das HQs aqui apresentadas, por sua vez, rompe também com certa imagem de sujeito universal presente no interior das HQs - a saber, de que se trata de uma linguagem produzida por homens, sobre homens e para homens, tendo aí os super-heróis enquanto gênero narrativo por excelência.

As aproximações entre HQs e temas como mulheres, feminino e gênero também são amplamente exploradas no interior da bibliografia mais recente dedicado ao estudo das HQs. Antes de abordá-las em particular, cabe destacar o campo mais recente dos comics studies, em que elas se inserem.

\section{Estudos recentes sobre HQs: a "indisciplina" como método}

Os estudos acadêmicos sobre histórias em quadrinhos (HQs) têm experimentado notável crescimento ao longo dos últimos anos. Tal constatação não é de todo nova, conforme atestam as introduções de boa parte dos vários livros lançados recentemente. Fato novo é o estabelecimento de um efetivo campo de estudos dedicado às HQs, sintetizado no mundo anglo-saxão pela expressão de língua inglesa comics studies.

Sua consolidação nas últimas duas décadas parece responder a um movimento mais amplo que ganha força desde as décadas de 1950 e 1960 e que advoga em defesa das HQs enquanto expressão cultural legítima. Artistas incorporam aspectos visuais das HQs em suas obras, exposições tomam HQs e 
seus personagens como tema principal e estudos acadêmicos dedicam-se a analisá-las como fenômeno da "cultura de massas". Em comum, postulam a necessidade de superar o estigma carregado, em especial, pelas revistas em quadrinhos ao longo dos anos de 1940 e 1950 e que resultaram em campanhas públicas por controle, censura e mesmo destruição de tais impressões (NYBERG, 1998).

Ao lado da afirmação do mérito cultural das HQs, observa-se a diversificação do mercado de HQs nos anos 1960, que pode ser creditada tanto pelas novas dinâmicas e pelo sucesso de vendas de uma editora como Marvel Comics, como também pelo surgimento de um circuito alternativo de produção e distribuição de HQs e que se tornaria conhecido como comix underground. Este é de maior interesse para os objetivos do artigo, na medida em que os trabalhos de nomes como Robert Crumb, Art Spiegelman, Gilbert Shelton, S. Clay Wilson partiam de um efetivo trabalho de pesquisa histórica e artística para defenderem a autonomia criativa e artística das HQs fora de campos bem estabelecidos da alta cultura. Em A Distinção, Pierre Bourdieu identifica uma série de práticas culturais presentes à época de redação do livro - o original foi publicado na França em 1979 - que, excluídas do arcabouço dos padrões de gosto assimilados pela cultura aristocrática, apontam para uma erudição própria que ajudaria a compensar a carência inicial de capital cultural por parte de determinados grupos (BOURDIEU, 2007, p. 81-82)3. Tais princípios inspirarão gerações posteriores de artistas e ajudarão a consolidar o formato graphic novel', que permite a elaboração de HQs com enredos mais extensos, complexos e livres desde o ponto de vista autoral (BAETENS; FREY, 2015; HATFIELD, 2005).

\footnotetext{
Para o autor, as HQs de então eram um exemplo de autodidatismo "novo", marcado pela inserção de seus agentes no sistema escolar o suficiente para adquirirem uma relação desencantada e mais autônoma com a cultura oficial, investindo seus esforços em terrenos excluídos desse universo. Contextualizando o livro de Bourdieu em relação aos sentidos sociais produzidos sobre a prática cultural dos quadrinhos, o autor reconhece que, naquela altura, os quadrinhos já possuíam uma trajetória consagrada ${ }^{3}$, definida a partir do estabelecimento de referências, HQs favoritas, o reconhecimento de desenhistas e autores, entre outros aspectos (BOURDIEU, 2007, p. 30). Um estudo fundamental sobre as configurações específicas do campo das bande dessinées na França e diretamente inspirado na teoria de Bourdieu foi desenvolvido por Boltanski (1975, p. 37-59).

${ }^{4}$ Graphic novels são publicações em quadrinhos que geralmente apresentam enredos com uma trama mais engenhosa, voltadas para um público mais velho. Ganha popularidade a partir de fins da década de 1970, com A Contract with God [1979], de Will Eisner (BAETENS; FREY, 2015).
} 
Já sobre os comics studies, trata-se de área bastante diversificada, pois permite o diálogo crítico entre estudiosos independentes e pesquisadores bem estabelecidos na academia; entre disciplinas como história, estudos de mídia, artes visuais, filosofia e teoria literária, entre outras; e entre revistas e editoras acadêmicas consagradas, que cada vez mais abrem espaço para artigos provenientes de pesquisas em torno das HQs, ao lado de uma série de periódicos acadêmicos dedicados exclusivamente à pesquisa sobre HQs. Listá-los seria tarefa exaustiva, mas uma sondagem rápida permite destacar os seguintes títulos: Comicalités, Comics Grid, European Journal of Comic Art, ImageText, International Journal of Comic Art, Journal of Graphic Novels and Comics e Scandinavian Journal of Comic Art.

Como resultado, são muitos os livros e coletâneas que partem de problemáticas tão distintas como memória, identidades, cotidiano e linguagem a partir das HQs, reconhecendo-as enquanto espaço privilegiado para se discutir tais temas. Ao mesmo tempo, há o interesse em consolidar o campo de estudos em torno das HQs através da elaboração de obras de referências, com destaque para uma série de readers contendo artigos fundamentais para a teoria e a história das HQs (HATFIELD; HEER; WORCESTER, 2013; HEER; WORCESTER, 2009; MILLER; BEATY, 2014). Em comum, assumem as HQs como agentes sociais que, por meio de formas bastante específicas de narrar graficamente, introduzem questões fundamentais acerca de temas como diferenças sociais e identitárias. Outro caminho para estudar as HQs passa por assumi-las não apenas como narrativas geradoras de representações, mas como objetos sob os quais circulam diversos agentes, como artistas, editores e leitores.

Tal diversidade parece atestar a "indisciplina" como condição definidora dos assim chamados comics studies, conforme sustenta Charles Hatfield (2010): pelas características próprias da linguagem das HQs, tal campo de conhecimento deve primar pelo constante desafio às convenções disciplinares - e suas respectivas fronteiras e delimitações - pré-estabelecidas e reforçadas pelos ditames da vida acadêmica. Sob um ponto de vista epistemológico, Hatfield sustenta que os comics studies deveriam possibilitar, pois, um exame permanente em torno de como, por quem e sob quais parâmetros o 
conhecimento é produzido no interior da academia. É uma leitura que se aproxima daquela desenvolvida por Henry Jenkins em "Should we discipline the study of comics?" [Devemos disciplinar o estudo das HQs?]. Mesmo advogando em defesa da organização disciplinar dos comic studies, o autor defende que ela deve se basear numa abordagem "radicalmente indisciplinar", alinhada ao caráter transgressor presente nos trabalhos de muitos artistas de HQs e sensível às contribuições críticas de criadores e leitores (JENKINS, 2012, p. 01-14). Desde um ponto de vista teórico-metodológico, a indisciplina dos comics studies advoga princípios como a necessidade de entrecruzamentos disciplinares, a ênfase em uma investigação que vá além da reafirmação de cânones e de uma história oficial e, por fim, a importância de uma ampla participação de artistas e leitores na reflexão crítica em torno das HQs. São princípios que exercitam aquilo que Frisch compreende como "autoridade compartilhada" (FRISCH, 1990), tendo como eixo orientador a HQ enquanto objeto cultural dotado de complexidade histórica e cultural.

\section{Problematizando a história oficial das HQS}

Nas muitas narrativas que constituem a história das HQs, de seus artistas e de seus personagens, é recorrente a afirmação de que as mulheres tiveram pouco espaço num meio dominado essencialmente por homens. Os cânones associados aos vários formatos de publicação - da tira cômica às graphic novels - são de artistas homens dedicados a produzir narrativas voltadas para leitores do sexo masculino. O caso das revistas de super-herói seria a expressão mais representativa do silenciamento da presença feminina nas HQs.

Tal afirmação é dotada de tons auto evidentes. Afinal de contas, quem ousaria duvidar que um personagem como Superman não reforça, em seu nome e no seu corpo, um poderio do corpo masculino? Ou que a Mulher Maravilha não conta com forte carga sexual, e que ganha ares quase anedóticos quando nos deparamos com as várias situações de bondage presente em suas HQs, que, por sua vez, apresentam curioso paralelo com certos fetiches sexuais de seu criador, William Marston? 
Os problemas dessa interpretação da história das HQs são vários, conforme mostra a bibliografia acadêmica mais recente. Num esforço por estabelecer as HQs no interior de um campo comum a estudos dedicados a outras práticas editoriais e visuais como os da história do livro, da cultura visual e imagem e das representações, diversos estudiosos têm buscado questionar tal narrativa. Um primeiro movimento pode ser observado a partir do esforço em mapear a atuação de artistas mulheres ao longo da história das HQs, tema que desenvolveremos em maior profundidade mais adiante. O nome mais conhecido a dedicar-se a esta tarefa é o de Trina Robbins (2013). Se tal esforço relacionase a uma abordagem arqueológica que pode ser identificada em autores como Art Spiegelman e Chris Ware, seu projeto de mapear as trajetórias de mulheres cartunistas insere-se num esforço por compreender-se, ela mesma, como uma artista de HQs cuja obra apresenta especificidades graças à sua condição de mulher. A iniciativa pioneira de Robbins certamente possibilitou uma profusão de trabalhos recentes que se debruçam sobre artistas mulheres de HQs.

Torna-se, pois, fundamental pensar uma escrita da História das HQs que estabeleça as mulheres como agentes da História. Ligada ao grupo de artistas associados ao comix underground dos anos 1960-1970, Robbins sintetiza o estabelecimento das HQs como bem cultural ao conciliar produção artística e pesquisa histórica de fôlego. Sua atuação, seja em trabalhos publicados no auge dos movimentos contraculturais dos anos 1960, seja promovendo clube de leitura feminino sobre HQs, expressa o esforço em sintetizar de maneira dinâmica a interação entre arte e história. Exemplo representativo pode ser encontrado na revista em quadrinhos editada por Robbins, em parceria com Willy Mendes, e publicada em julho de 1970, intitulada It Ain't Me, Babe. A capa, assinada por Robbins, traz algumas personagens femininas já bem conhecidas da história das HQs e da cultura pop - Olívia Palito, Mulher-Maravilha, Capitã Marvel, Luluzinha, Sheena e Elsie the Cow - de punho em riste, como se estivessem marchando em defesa da "libertação da mulher". Mais especificamente, as autoras eram contrárias aos enredos machistas das HQs, que reservavam às mulheres papeis secundários e restritos; o famoso aviso de “mulheres não entram”, regra fundamental do clube de meninos do Bolinha, na 
série Luluzinha é sintomático dos limites impostos às personagens femininas. $\mathrm{Na}$ publicação, Luluzinha responde a esse impedimento com um sonoro "Foda-se essa merda!". A revista recebia contribuições de artistas mulheres e representa um marco no interior dos comix underground, até então marcadamente masculinos.

O esforço por uma escrita da história que priorize o resgate de personagens e autoras femininas se percebe também na produção historiográfica de Robbins. Seus trabalhos apresentam como ponto em comum o esforço de décadas em levantar e obter documentação sobre mulheres e HQs via jornais, revistas, fanzines e depoimentos orais. Dentre seus estudos, destacam-se uma história de artistas mulheres na produção de HQs (ROBBINS, 2013), e a publicação de material original de desenhistas e escritoras que produziram revistas em quadrinhos protagonizadas por mulheres em apoio à atuação dos Estados Unidos durante a Segunda Guerra Mundial (ROBBINS, 2017). O mapeamento das mulheres nas HQs também é trabalhado por Robbins a partir do recorte do gênero narrativo dos super-heróis, por vezes associado ao universo masculino, salvo raras exceções (ROBBINS, 1997). Suas obras buscam ir além de personagens mais conhecidas do grande público e introduzem ao leitor uma plêiade de protagonistas do sexo feminino. São um prato cheio para pesquisadores e pesquisadoras interessados em aprofundar os estudos sobre HQs e mulheres.

O Brasil ainda carece de trabalhos de fôlego na linha apontada por Robbins. Uma exceção a esse cenário é o trabalho de Ediliane Boff (2014), dedicado a elencar, numa primeira parte, as diversas imagens de mulheres produzidas ao longo da história das HQs. A autora avança para além das super-heroínas das revistas em quadrinhos, ao lembrarmo-nos da presença feminina em family strips como Pafúncio e Marocas ${ }^{5}$, em tiras infantis como Nancy ou aquela que é mais conhecida personagem das HQs brasileiras - Mônica. Na segunda parte do seu trabalho, dedica-se a uma série de estudos de caso, mesclando autoras

\footnotetext{
5 Tiras cômicas com enredos centrados no ambiente familiar. Traduzida no Brasil como "Pafúncio e Marocas", a tira Bringin' up father, criada por George McManus e publicada desde 1912, foi uma das Family strips que mais fez sucesso junto ao público leitor de jornal. Produzida nos EUA, foi traduzida e publicada em países da Europa e América Latina.
} 
brasileiras e espanholas com trabalhos publicados desde a segunda metade do século XX, tendo como pano de fundo um panorama internacional da produção feminina de HQs. Como resultado, temos um relevante panorama sobre as mulheres no mundo dos quadrinhos, verticalizado a partir de estudo comparativo entre Brasil e Espanha.

O trabalho de Boff aponta a necessidade de novos estudos, desde recortes mais precisos e a partir de critérios como formatos de publicação, circulação e perfil de público leitor. Tais aspectos podem contribuir para análises mais detidas sobre realidades bastante específicas envolvendo o papel das mulheres na produção de HQs. Um trabalho interessante nesse sentido é o de Jessica Eugênio, cuja dissertação de mestrado em Sociologia trata da produção e circulação de quadrinhos de mulheres e para mulheres em circuitos alternativos como feiras, fanzines e distribuição independente via online. Sua pesquisa se vale das dinâmicas das redes sociais e as enfrenta sem hesitações, através da imersão da pesquisadora em grupos de Facebook, da sua participação em eventos de HQs e de entrevistas coletadas ao longo da pesquisa (EUGÊNIO, 2017).

\section{A construção de um objeto de estudos: o caso da Mulher Maravilha}

Também devem ser mencionadas pesquisas acadêmicas que põem em xeque certos truísmos em torno de personagens bem conhecidos de leitores e historiadores das HQs. Um dos estudos de casos que permitem maiores problematizações desde o ponto de vista histórico é o da Mulher Maravilha. Personagem de origem controversa, foi criada por William Moulton Marston, psicólogo que se dizia feminista e admirador das mulheres, além de se autodeclarar inventor do detector de mentiras - apesar de Marston não destacar sua esposa, Elizabeth Holloway Marston, como colaboradora direta nas pesquisa que levaram à invenção do equipamento. Elizabeth também teria servido de inspiração para a criação da personagem Mulher Maravilha, bem como Olivia Byrne, parceira de William e Elizabeth Marston num relacionamento poliamoroso.

Para William Marston (1945, apud LEPORE, 2014, p. 190-191, tradução nossa), a Mulher Maravilha era uma "propaganda psicológica com vistas ao novo tipo de mulher que, na minha opinião, deveria dominar o mundo." A despeito de suas 
intenções feministas, a saída adotada, em cada HQ, de expor a personagem amarrada e em situações que remetem a práticas sexuais de bondage mais pareceu, para muitos, expressar fetiches masculinos do autor e dos leitores, masculinos, de comic books. A história da personagem fica ainda mais rica ao lembrarmo-nos do seu êxito comercial ao longo dos anos de 1940 e 1950, quando a maior parte das revistas de super-heróis que inundaram o mercado de revistas durante a Segunda Guerra Mundial encontravam dificuldades para manter suas vendas após o conflito. É claro que sua popularidade ajudou a manter a série no mercado, o que pode ser confirmado pelas heroínas que surgiram no mercado na esteira do sucesso da personagem de Marston. Mas as razões contratuais envolvendo a DC Comics e seu criador, que estipulava que seus herdeiros recuperariam todos direitos de posse da marca/personagem caso o título com o nome dela fosse descontinuado, certamente contribuíram para sua longa permanência nas bancas de revista (GABILLIET, 2010, p. 34-35).

A história da personagem, de William Marston, Elizabeth Marston e Olivia Byrne é analisada em detalhes naquela que, certamente, é uma das maiores obras de fôlego sobre uma personagem de HQs. Em A História Secreta da Mulher Maravilha, Jill Lepore, especialista em história dos EUA e professora na Universidade de Harvard, procura pensar as relações entre HQs e representações políticas a partir da Mulher Maravilha e o feminismo. Para a autora,

A Mulher-Maravilha não é apenas uma princesa amazona que usa botas fabulosas. Ela é o elo perdido numa corrente que começa com as campanhas pelo voto feminino nos anos de 1910 e termina com a situação conturbada do feminismo um século mais tarde. O feminismo construiu a Mulher Maravilha. E, depois, a MulherMaravilha reconstruiu o feminismo - o que nem sempre fez bem ao movimento. (LEPORE, 2014, p. XIII, tradução nossa)

Dona de um texto objetivo e acessível, Lepore vale-se de vasta documentação - incluindo fontes inéditas ligadas a William Marston - para analisar as conexões entre a super-heroína e as lutas femininas do século XX onde, à relevância das disputas sobre o feminino que se deram através da Mulher-Maravilha, contrapõe-se o silêncio da história das mulheres em relação à personagem (LEPORE, 2014, p. 296). Isso the possibilita traçar uma trajetória dinâmica da super-heroína, marcando as transformações vividas por ela num 
diálogo aberto com as mudanças em torno do lugar das mulheres no mundo contemporâneo, ao mesmo tempo em que possibilita narrar uma história original das HQs desde o ponto de vista da personagem.

Herdeira das sufragistas, a HQ da Mulher Maravilha celebrou a liberdade das mulheres na primeira metade dos anos 1940, em pleno auge das revistas em quadrinhos, ao ponto de, nas suas revistas, veicular uma seção como "As Mulheres-Maravilha da História", celebrando a história feminina ao destacar trajetórias de mulheres importantes na História. Porém, perdeu sua força após a morte de William Marston, em 1947, e na década seguinte, quando sucumbiu às críticas públicas sofridas pelas revistas em quadrinhos, boa parte delas resumidas no livro do psiquiatra Fredric Wertham, The Seduction of the Innocent [1954]. Tida como “a contraparte lésbica do Batman”, a ela associaram-se casos de delinquência juvenil, tendo em vista que a HQ “[...] retrata a aversão extremamente sádica em relação a todos os homens numa estrutura claramente lésbica” (WERTHAM, 1954, p. 192-193 apud LEPORE, 2014, p. 269, tradução nossa).

Nesse momento, as HQs da Mulher Maravilha perderam em protagonismo feminino e a personagem oscilou entre conselheira amorosa, babá e aspirante a estrela de cinema, sempre à procura de um casamento. A seção "As MulheresMaravilha da História" foi substituída por uma série sobre casamentos (LEPORE, 2014, p. 272). Na década seguinte, quando a Mulher Maravilha passava por uma verdadeira crise de identidade editorial, ao abdicar de seus poderes para viver no mundo dos homens, assumindo uma faceta de espiã e de lutadora de artes marciais para combater o crime, a força da sua conexão histórica com os movimentos de emancipação feminina é resgatada em fins dos anos 1960, não sem tensões entre as diversas vertentes políticas do feminismo presentes então. O grupo Redstockings ${ }^{6}$ do Movimento de Libertação das Mulheres, associado ao feminismo radical fundado em 1969, apontava que:

\footnotetext{
6 Também conhecidas como Redstockings of the Women's Liberation Movement, o coletivo acreditava que a submissão feminina é uma estratégia de adaptação diante da desigualdade de poder entre homens e mulheres no patriarcado que, por sua vez, está na base e orienta outras formas de opressão. Por isso, consideram que a libertação feminina depende da conscientização feminina e coletiva através de discussões, reuniões e atividades políticas, e deve resultar, numa síntese entre teoria e prática, na afirmação da força presente nos corpos femininos subjugados - e, por isso, permite às Redstockings afirmar que "o pessoal é político".
} 
A Mulher Maravilha também reflete a atitude antipopular das 'feministas liberais' e dos matriarquistas que buscam heroínas sobrenaturais e modelos 'míticas', ignorando ou denegrindo as conquistas e lutas das mulheres reais. Isso leva à linha da "mulher liberada", individualista, que nega a necessidade de um movimento e implica que, quando as mulheres não conseguem algo, é por culpa delas. (GRUPO REDSTOCKINGS, 1975, p. 29 apud LEPORE, 2014, p. 293, tradução nossa)

Cabe destacar que o trabalho de Lepore rapidamente repercutiu na bibliografia de maneira crítica, o que indica o dinamismo e a vitalidade do tema de investigação e, de forma mais ampla, da pesquisa sobre HQs. Pesquisador bastante atuante no interior dos comic studies, Noah Berlatsky publicou sua pesquisa dedicada a uma leitura atenta das HQs da Mulher Maravilha publicadas entre 1941 e 1948 no mesmo ano que The Secret History of Wonder Woman, o que pode ter dificultado, em parte, que seu livro obtivesse maior repercussão crítica. A partir de uma análise visual atenta à linguagem e aos códigos caros às HQs e de uma discussão sólida com outras historiadoras das HQs, como a já mencionada Trina Robbins e Lillian Robinson, Berlatsky debate em profundidade a representação de temas como fetichismo, sexualidade e lesbianismo nos quadros das HQs da personagem, pouco explorados por Lepore em seu trabalho (BERLATSKY, 2015).

Infelizmente, por vezes a análise se prende a certa teorização excessiva e que compromete a fluidez da análise e da narrativa, além de soarem excessivamente especulativas e sem lastro histórico. Porém, as discussões de Berlatsky ganham relevo quando passam para leituras mais detidas sobre histórias da Mulher Maravilha; aqui o autor parece se sentir muito mais à vontade, ao contrário de Lepore, que prioriza todo os agentes que giram em torno da HQ - autores, editores, leitores etc. - e pouco se dedica a análises de fôlego sobre as próprias HQs. Por exemplo, o primeiro capítulo de Berlatsky é quase todo dedicado a uma reflexão freudiana sobre incesto e tem por objeto principal um único número da revista Wonder Woman. No fim das contas, as análises de Lepore e Berlatsky podem ser vistas como complementares - do ícone cultural à riqueza estética e conceitual de uma HQ - e contribuem para uma visão mais complexa sobre a Mulher Maravilha no interior da história das HQs. 
A discussão também já encontra ecos interessantes no Brasil, como a recente dissertação de mestrado em História - já editada em livro - de Savio Queiroz Lima. Na esteira de Lepore, mas dialogando com referências trazidas, em especial, pelo historiador das HQs Les Daniels, as disputas pelos sentidos do feminino são explorados por Savio Lima desde um "projeto de educação antimachista" que originou a personagem (LIMA, 2017, p. 146), atentando para tópicos como a composição do uniforme da Mulher Maravilha ou sua releitura pela revista feminista Ms Magazine durante os anos de 1970. Em especial, merece destaque o fato de que sua pesquisa consegue ressaltar a vitalidade da figura da Mulher Maravilha no imaginário do Tempo Presente, ao destacá-la como ícone cultural de consumo, em seus usos no debate político eleitoral como um contraponto crítico à campanha de Donald Trump, nas críticas que ainda sofre por grupos feministas contemporâneos e nas releituras em novos formatos editoriais, como a graphic novel elaborada por um nome reconhecido das HQs como Grant Morrison (LIMA, 2017, p. 150-152).

\section{Perspectivas para o estudo das relações entre mulheres e HQs: trajetórias de artistas}

Outro caminho passa pela análise da trajetória de artistas mulheres, buscando dar visibilidade à sua atuação na composição do mercado editorial de HQs. Nesse sentido, os estudos pioneiros de Trina Robbins podem contribuir bastante, conforme apontado acima. A artista de HQs June Tarpé Mills tem sua produção indústria dos comics analisada por Nogueira (2015), a partir da série Miss Fury. Sua pesquisa sinaliza para a singularidade de Mills e sua inserção num mercado de revista em quadrinhos ainda majoritariamente masculino. Através de sua Miss Fury, a autora pôde ir além da mera representação de estereótipos associados à figura feminina ao introduzir laços autobiográficos na personagem e lidar com temas delicados até então, como a violência contra as mulheres (NOGUEIRA, 2015, p. 78-79). Para Nogueira, a obra de Mills em Miss Fury caminha em sintonia com os debates ligados à condição feminina dos anos 1920 e 1940 nos Estados Unidos. 
O trabalho de Mills em Miss Fury - chamada também de Mulher Pantera nas primeiras traduções brasileiras da personagem, na década de 1940 - também é discutido por Jaquelina Cunha a partir de uma perspectiva comparada em relação a Marston e sua Wonder Woman (CUNHA, 2016). Atenta às diferenças entre cada personagem, a autora consegue estabelecer uma reflexão de conjunto que aponta as possibilidades e os limites das representações do feminino em revistas em quadrinhos dos anos 1940. Voltadas para um consumo rápido e efêmero, as revistas desse período eram produzidas sob um ritmo intenso, sendo não raro vistas como um divertimento menor ou mesmo uma subliteratura, voltadas a jovens, trabalhadores ou soldados em guerra.

A partir da comparação entre ambas as personagens, Cunha (2015, p. 140) chega à sugestiva conclusão de que “[...] a criação de William Moulton Marston e a criação de Tarpé Mills empoderavam a mulher no âmbito do texto, mas a objetificava no momento da ilustração." Ou seja, se Mulher Maravilha e Miss Fury eram personagens com roteiros simpáticos à emancipação feminina e à revisão das designações usuais destinadas às mulheres no mundo do trabalho, seus quadros/vinhetas representavam as mulheres de maneira submissa ou com alto grau de sexualidade, para o prazer visual dos leitores masculinos.

Esforço similar em compreender a atuação das mulheres no mundo das HQs incide em casos como o brasileiro, através da análise de artistas brasileiras. Maria da Conceição Francisca Pires tem desenvolvido pesquisas recentes em torno de Fabiane Langona, mais conhecida pelo pseudônimo "Chiquinha". Pires desenvolve uma reflexão que busca compreender como pautas feministas são incorporadas, de maneira dinâmica, no humor gráfico e processadas esteticamente numa $\mathrm{HQ}$, evitando, assim, incorrer em essencialismos em torno de um "humor feminino" - sem abdicar, porém, da necessidade de pensar a ideia de um "humor feminista" (PIRES, 2019b, p. 305-306). As análises das HQs de Chiquinha exploram noções como grotesco e humor, desde os campos da História Cultural e, mais especificamente, da História Cultural do Humor, para discutir as estratégias traçadas pela quadrinista para colocar em xeque padrões de beleza que se impõem sobre o corpo da mulher (PIRES, 2019a, p. 71-87; PIRES, 2019b, p. 302-316). 
Os estudos sobre História Cultural do Humor desenvolvidos por Pires têm se desenvolvido em diálogo com os trabalhos de historiadoras como Cintia Crescêncio e Mara Burkart. Sem dúvida, já podem ser considerados como referências nesse campo, vide o dossiê "O Humor das Mulheres e as Mulheres no Humor”, publicado na revista Ártemis em 2018. Ainda que não manifeste no título do dossiê seu interesse explícito nas HQs, o dossiê conta com artigos das já citadas Burkart, Nogueira, Crescêncio e outras, dedicados à atuação de mulheres no mundo das HQs. Inspirada por Michelle Perrot, o artigo de Crescêncio (2018, p. 55-56), por exemplo, busca superar os "silêncios do humor" e recuperar a "produção com assinatura de mulheres" em charges, cartuns e HQs.

Daiany Dantas analisa a produção - em grande parte desconhecida por muitos até hoje - de Marguerita Fahrer, autora de "Margarida, a Incrível Mulher Moderna”, publicado na revista Mais! durante a década de 1970 (DANTAS, 2006). Trata-se de uma entrada bastante instigante para discutir as representações da mulher nos anos de ditadura no Brasil. Novamente, observa-se o uso do procedimento metodológico comparativo, no qual a obra de Fahrer é analisada ao lado da série de tiras cômicas "Mulheres Alteradas", de Maitena Burundena, publicada ao longo dos anos 1990. Dantas discute a representação do corpo feminino em ambos os trabalhos, pensando-o como espaço ambivalente de resistência aos autoritarismos e às pressões da modernidade a partir do grotesco. O trabalho, porém, poderia apresentar conclusões mais claras a partir da análise comparada, e tópicos como as tensões entre o controle sobre o corpo feminino e luta política de resistência aos regimes autoritários no Brasil, via Fahrer, ou as transformações em torno do feminino na Argentina dos anos 1990, através de Mulheres Alteradas, seguem em aberto.

No campo das chamadas webcomics, a recente dissertação de Carolina Ito Messias (2018) apresenta um importante panorama da produção brasileira de HQs de autoria feminina na internet. As autoras discutidas por Messias destacam-se pela liberdade criativa e por escaparem dos crivos editoriais que, segundo a autora, parecem destacar a produção de graphic novels de viés autobiográfico. Nas publicações digitais, os enredos são mais ficcionais e o processo criativo passa por uma constante negociação entre autoras e leitoras, com implicações no mercado impresso (MESSIAS, 2018, p. 99). 
Identidades femininas enquanto campo de investigação no Tempo Presente

As relações entre mulheres e identidades seguem também como tema a ser mais desenvolvido nas pesquisas brasileiras. A articulação entre estudos de gênero, raça e identidades trata-se de temática já bem avançada entre estudiosas anglo-saxãs dos comics studies, vide estudos sobre identidades judaica (OKSMAN, 2016) e asiática (OGl et al., 2019) desenvolvidos a partir de campos como os da História das Mulheres e dos estudos feministas. Em comum, o foco em graphic novels produzidas por mulheres. Como dito acima, trata-se de um formato que prioriza a afirmação de uma marca autoral em HQs de maior fôlego narrativo, o que the possibilita explorar amplamente temas ligados a subjetividades e testemunhos em perspectiva autobiográfica. É possível aqui pensar numa ideia de "testemunho gráfico" - esta é a expressão que serve de título ao livro de Hillary Chute.

A renomada pesquisadora de HQs adota a expressão "testemunho gráfico" para enfatizar como o cruzamento de texto e imagem típicos da linguagem das HQs opera num registro de "narrar e ver" que amplia ideias usualmente associadas aos estudos de trauma e do não representável: de acordo com Chute, as obras de artistas como Lynda Barry, Marjane Satrapi e Alison Bechdel, entre outras mais, não realizam uma narrativa em que a identidade é definida pelo trauma e pelo não dito. Ao invés disso, afirmam seu valor da presença, ainda que contingente e fragmentado pela própria distribuição de imagens em sequência que marca a linguagem das HQs. A tensão entre imagens e textos em sequência e a escrita autobiográfica das mulheres dá possibilidade a uma expansão do "idioma da testemunha", segundo a autora (CHUTE, 2016, p. 2-3).

A título de exemplo sobre as ricas possibilidades de articulação entre estudos das mulheres e das identidades a partir das HQs, vale destacar a análise sobre o protagonismo de mulheres negras nas HQs, conforme promovido por Deborah Whaley, em Black Women in Sequence. Passando por formatos de publicação como tiras cômicas, comix underground e graphic novels, Whaley (2016, p. 8) discute como a negritude associada a autoras, obras e leitoras de HQs se torna um campo privilegiado para processar noções ligadas a temas como 
política, nação e sexualidade. É a ascensão daquilo que a autora classifica como "sujeitos sequenciais" [sequential subjects], quando as HQs articulam - em cada tira, revista ou livro - tais questões de forma dinâmica, propiciando uma visibilidade privilegiada, ainda que, por vezes, contraditória, tensa e prenhe de possibilidades, da condição da negritude feminina em determinados contextos (WHALEY, 2016, p. 182).

Um rico caminho que se avizinha a partir do tema das identidades femininas é a sua articulação aos estudos de gênero e LGBTQ+. Uma recente coletânea buscou discutir as relações entre gênero, identidades queere o público consumidor de HQs de super-herói (GOODRUM; PRESCOTT; SMITH, 2018). As identidades queer também são analisadas por Francine Oliveira a partir de HQs brasileiras publicadas desde meados dos anos 1980, com foco no que identifica como "sexualidades divergentes" e a partir dos estudos de humor. Como estudos de caso, aborda HQs brasileiras, de "Super Gay", de Watson Portela, a "Mariana e Claudinha", de Fernando Duarte, passando pela obra mais recente de Laerte Coutinho (OLIVEIRA, F., 2014).

Cabe determo-nos nessa última autora de HQs. Sem pretender soar exaustivo, é possível mapear um conjunto de trabalhos em torno de Laerte, um dos principais nomes da HQ nacional e que, no início do século XXI, explicitou suas inquietações em relação à sua sexualidade e modo de ser a partir de um personagem já consolidado, Hugo, que assume a identidade transgênera de "Muriel". Mais, Laerte colocou em questão uma série de convenções sexuais de toda ordem e, em meio a incompreensões de todos os tipos, reconstruiu sua trajetória pública (BUCCHIONI, 2016; OLIVEIRA, C., 2014), numa estética de si que mobiliza seu corpo e sua arte numa performance, obra em movimento, a favor da liberdade. Em Laerte, existir é resistir às convenções. Os estudos mais recentes sobre a autora e sua obra convergem em estabelecer a categoria de "transgênero" como fundamental para compreendê-la, valendo-se também dos estudos de identidade cultural, via Stuart Hall, das reflexões de Gilles Deleuze sobre devir e fronteira e as contribuições em torno da ideia de gênero conforme desenvolvidas por Judith Butler, entre outros (CAVALCANTE, 2014; NÓBREGA FILHO, 2016; THEODORO, 2016). 
Um desafio para as pesquisas brasileiras nesse campo, é incluir como problema de investigação as representações de masculinidades nas HQs. Discussões centradas nas masculinidades desde o ponto de vista do corpo super-heroico (PARSON; SCHATZ, 2020) e da leitura de HQs com aprendizagens de valores e noções que configuram identidades masculinas junto ao público leitor (MAIGRET, 1999, p. 05-27) podem resultar em interessantes pesquisas a serem desenvolvidas no Brasil.

Debater identidades femininas a partir de personagens pode contribuir para lançar novas luzes sobre obras que, a princípio, não seriam lidas sob o prisma da relação entre sexualidades e poder. Em recente artigo sobre a produção do artista brasileiro Marcelo D’Salete, Jasmin Wrobel analisa o papel das personagens femininas em trabalhos como Cumbe e Angola Janga. São obras que caminham entre a história e a ficção para dar conta de episódios ligados aos séculos de escravidão negra no Brasil, e assim tem se dado sua recepção junto ao público e à crítica especializada. Wrobel aprofunda tal leitura ao ressaltar como, em ambos os trabalhos, as personagens femininas têm um papel fundamental para explicitar ações ligadas à violência colonial - entendida também como colonização sexualizada do corpo feminino africano - e de resistência e emancipação. Demonstra como, a partir das mulheres, D'Salete narra uma história complexa das pessoas escravizadas no Brasil, assumindo-as como sujeitos da História (WROBEL, 2019, p. 99-116).

\section{Rumo a uma história feminista das HQs}

Desde 2006, uma coleção estadunidense estabelece um conjunto de HQs produzidas por autores consagrados e iniciantes e em formatos os mais diversos, visando apresentar um panorama sumário da produção de HQs num dado ano. The Best American Comics (TBCA) termina, pois, por sintetizar as tendências e possibilidades desse meio de expressão, mas também as transformações no campo das HQs no tempo presente. A cada ano, a série é organizada por um nome reconhecido na área, que seleciona as HQs a serem apresentadas e redige um prefácio apresentando o volume sob sua responsabilidade. A mudança no perfil é clara: entre 2006 e 2010, Lynda Barry foi a única artista do sexo feminino 
a assumir tal função; de 2011 a 2015, Alison Bechdel e Françoise Mouly foram responsáveis por dois volumes da TBCA; entre 2016 e 2019, três dos quatro volumes foram organizados por mulheres: Roz Chast, Phoebe Gloeckner e Jillian Tamaki.

Observa-se, no caso, não só a presença feminina selecionando, organizando e orientando as tendências das HQs, mas também uma inquietação em relação à especificidade de uma curadoria marcada pelo olhar feminino: se, em 2010, Neil Gaiman era celebrado como um bom nome para organizar o volume da TBCA daquele ano por ter ampliado o público leitor feminino de HQs através da sua graphic novel Sandman, em 2012 a editora Françoise Mouly apresentou suas dúvidas e interesses para o estabelecimento de critérios de seleção daqueles que seriam os "melhores quadrinhos dos EUA" daquele ano. Para tal, apropriou-se criativamente do estilo de alguns nomes canônicos da história das HQs para fazer ecoar sua própria voz e afirmar a necessidade de inserir, "em especial, mulheres jovens - quero dizer, há mais cartunistas mulheres do que nunca!". De certa forma, a interação entre imagem e texto explicita as contradições e as possibilidades de se colocar em xeque certa narrativa historiográfica canônica sobre as HQs a favor de critérios outros para pensar seu lugar no tempo presente (MOULY, 2012, p. XV).

Longe de pretender soar exaustivo, este breve levantamento de trabalhos acadêmicos indica o recente interesse em compreender as mulheres não apenas a partir de suas representações nas páginas de HQs, mas também a partir de suas práticas, para retomar a clássica e, por vezes, esquecida formulação de Roger Chartier (2002). No caso das HQs, isso significa atentar para as propriedades bastante específicas da sua linguagem, em como ela se constrói socialmente num dado período histórico e em como tais elementos potencializam ou silenciam discursos em torno do feminino. Isso significa ser necessário atentar não somente para as relações entre imagens e textos, mas para as formas de publicação, sua recepção e a constituição de um público leitor, e em como e em que medida a presença feminina se apropria e transforma tais esferas que constituem a HQ enquanto prática cultural. É de tal forma que os quadrinhos podem se tornar complexos objetos de análise para todo aquele se 
aventura a investigá-los, pois empreendem representações únicas do passado a partir das questões de uma dada época. São fontes não apenas de representações da realidade, mas também carregam consigo sensibilidades e formas de ver, assim como silêncios e esquecimentos, processados criativamente por meio da sua linguagem gráfica.

A partir de abordagens e recortes diversos, o conjunto de trabalhos aqui analisados aponta que uma leitura feminina das HQs modifica todas as esferas definidoras dessa arte. Em linhas gerais, são obras que se preocupam em compreender a especificidade da abordagem feminina no universo da produção criativa de HQs, indicando a importância de uma epistemologia feminina e feminista a favor de outras narrativas gráficas que enfatizem opressões, poderes cotidianos e os desafios contemporâneos impostos à condição de ser mulher. Por fim, gostaria de ressaltar três útimos aspectos relativos às obras aqui discutidas.

Em primeiro lugar, merece destaque a abertura do campo para o diálogo interdisciplinar. O breve levantamento aqui apresentado trouxe trabalhos oriundos de áreas tão diversas como Comunicação, História, Letras e Sociologia, entre outras. A interação entre campos disciplinares os mais variados também é perceptível no interior desses estudos, ainda que não haja espaço para desenvolver este argumento aqui. Acima de tudo, vale pensar a interdisciplinaridade desde a lógica dos estudos feministas e de gênero (BUTLER, 2015). As discussões aqui apresentadas permitem aprofundar a ideia dos comics studies enquanto uma (in)disciplina que, ao questionar procedimentos liturgias e processos de disciplinarização já há muito estabelecidos em outras áreas, pode constituir-se numa referência acadêmica privilegiada para o debate político do nosso tempo?.

\footnotetext{
Inspiro-me aqui nas possibilidades aventadas para a historiografia desde uma perspectiva indisciplinada, conforme sugeridas no conjunto de artigos reunidos na coletânea A história indisciplinada e, em especial, pelos trabalhos de Arthur Ávila (ÁVILA, Arthur. O que significa indisciplinar a história? In: ÁVILA, Arthur; NICOLAZZI, Fernando; TURIN, Rodrigo (orgs.). A História (in)disciplinada: teoria, ensino e difusão do conhecimento histórico. Vitória: Milfontes, 1999. p. 19-52) e Maria da Glória Oliveira (OLIVEIRA, Maria da Glória. A história disciplinada e seus outros: reflexões sobre as (in)utilidades de uma categoria. In: ÁVILA, Arthur; NICOLAZZI, Fernando; TURIN, Rodrigo (orgs.). A História (in)disciplinada: teoria, ensino e difusão do conhecimento histórico. Vitória: Milfontes, 1999. p. 53-72).
} 
Um segundo aspecto que merece atenção é a constatação do desenvolvimento de pesquisas acadêmicas de maior fôlego que colocam em primeiro plano o debate do feminino nas HQs. Já é possível falar num efetivo corpus bibliográfico consolidado internacionalmente, a partir do estabelecimento dos chamados comics studies. No Brasil, as pesquisas buscam dar conta de tal cenário, debatendo à altura com a ampla bibliografia internacional já existente sobre o tema. A grande maioria das obras aqui apresentadas assumem nomes como os de Trina Robbins, Hillary Chute e Jill Lepore, entre outras, como referências fundamentais para seus trabalhos. O esforço em dialogar com autoras e pesquisas estrangeiras ajuda a consolidar as análises e demonstra a relevância das teses e dissertações aqui analisadas, ao fortalecerem o campo de estudos sobre HQs a partir da perspectiva das mulheres.

Por fim, um terceiro aspecto passa pelos caminhos que os trabalhos analisados sugerem para pesquisas futuras. Um elemento comum parece passar pelas interações teóricas entre feminismos e linguagem das HQs. O caráter fragmentado e serial das HQs, fortemente dependente da interação com leitores, conforme destacado por Chute, constitui uma chave fundamental para a representação do outro. Desdobra-se daí suas implicações para a construção de subjetividades, a partir de temas e noções como corpo, intimidade e grotesco. Além disso, a articulação entre diversas identidades - raça, nacionalidades, classes etc. - sob a mediação do feminino em HQs indica todo um campo de possibilidades para o estudo das mulheres nas HQs.

Em 2014, o editor Scott McCloud redigiu um breve texto de apresentação dos trabalhos de Raina Telgemeier, Fanny Britt e Isabelle Arsenault intitulado “Meninas leem". McCloud remete a outro texto, escrito em 2004, no qual prenunciava que, em vinte anos, será possível observar a consolidação de uma pujante "indústria feminina de quadrinhos", composta por autoras, editoras e leitoras (MCLOUD, 2014, p. 75-77). Se esse cenário parecia fantasia e exercício de futurologia em 2004, a participação ativa de mulheres em todas as esferas de produção cultural de HQs nos dias de hoje parece tornar a predição de McCloud bastante plausível. 


\section{Referências}

BAETENS, Jan; FREY, Hugo. The graphic novel: an introduction. New York: Cambridge University Press, 2015.

BERLATSKY, Noah. Wonder woman: bondage and feminism in the Marston/Peter Comics, 1941-1958. New Brunswick: Rutgers University Press, 2015.

BOFF, Ediliane. De Maria a Madalena: representações femininas nas histórias em quadrinhos. 2014. Tese (Doutorado em Comunicação) - Universidade de São Paulo, São Paulo, 2014.

BOLTANSKI, Luc. La constitution du champ de la bande dessinée. Actes de la recherche en sciences sociales, [S.L.], v. 1, n. 1, p. 37-59, jan. 1975.

BOURDIEU, Pierre. A distinção: crítica social do julgamento. São Paulo; Porto Alegre: Edusp: Zouk, 2007.

BUCCHIONI, Tulio Heleno. Laerte "vestido de mulher": uma investigação sobre representações de gênero e sexualidade na mídia. 2016. Dissertação (Mestrado em Antropologia Social) - Universidade de São Paulo, São Paulo, 2016.

BUTLER, Judith. Problemas de gênero: feminismo e subversão de identidade. 8. ed. Rio de Janeiro: Civilização Brasileira, 2015.

CAVALCANTE, Laís. Quero deixar de ser um menino dependente para ser uma mulher autônoma: os casos transgêneros nas tirinhas de Laerte Coutinho. 2014. Dissertação (Mestrado em História) - Universidade Federal de Campina Grande, Campina Grande, 2014.

CHARTIER, Roger. A história cultural entre práticas e representações. 2. ed. Lisboa: Difel, 2002.

CHUTE, Hillary. Disaster drawn: visual witness, comics, and documentary form. Cambridge: Harvard University Press, 2016.

CORBIN, Alain; VIDAL, Laurent. Alain Corbin o prazer do historiador. Revista Brasileira de História, São Paulo, v. 25, n. 49, p. 11-31, jan./jun. 2005.

CRESCÊNCIO, Cintia Lima. As mulheres ou os silêncios do humor: uma análise da presença de mulheres no humor gráfico brasileiro (1968-2011). Ártemis, João Pessoa, v. 26, n. 1, p. 53-75, jul./dez. 2018.

CUNHA, Jaqueline dos Santos. A representação feminina em Mulher Pantera e Mulher Maravilha. 2016. Dissertação (Mestrado em Estudos da Linguagem) Universidade Federal de Goiás, Catalão, 2016. 
DANTAS, Daiany Ferreira. Sexo, mentiras e HQ: representação e autorrepresentação das mulheres nas histórias em quadrinhos. 2006. Dissertação (Mestrado em Comunicação) - Universidade Federal de Pernambuco, Recife, 2006.

EUGÊNIO, Jéssica Daminelli. Elas fazem HQ!: mulheres brasileiras no campo das histórias em quadrinhos independentes. 2017. Dissertação (Mestrado em Sociologia Política) - Universidade Federal de Santa Catarina, Florianópolis, 2017.

FRISCH, Michael. A shared authority: essays on the craft and meaning of oral and public history. New York: New York University Press, 1990.

GABILLIET, Jean-Paul. Of comics and men: a cultural history of american comic books. Jackson: University Press of Mississipi, 2010.

GOODRUM, Michael; PRESCOTT, Tara; SMITH, Philip (orgs.). Gender and the superhero narrative. Jackson: University Press of Mississipi, 2018.

HATFIELD, Charles. Indiscipline, or, the condition of Comics Studies.

Transatlantica, [Paris], n. 1, sept. 2010. Disponível em: http://journals.openedition.org/transatlantica/4933. Acesso em: 27 fev. 2020.

HATFIELD, Charles. Alternative comics: an emerging literature. Jackson: University Press of Mississipi, 2005.

HATFIELD, Charles; HEER, Jeet; WORCESTER, Ketn (orgs.). The superhero reader. Jackson: University Press of Mississipi, 2013.

HEER, Jeet; WORCESTER, Kent (orgs.) A comics studies reader. Jackson: University Press of Mississipi, 2009.

JENKINS, Henry. Should we discipline the study of comics? In: DUNCAN, Randy; SMITH, Matthew (orgs.). Critical approaches to comics: theories and methods. New York/London: Routledge, 2012. p. 01-14.

JIMÉNEZ, Carla et al. Mulheres quebram o jejum das ruas no Brasil com manifestações contra Bolsonaro. El Pais, São Paulo, 30 set. 2018. Disponível em: https://brasil.elpais.com/brasil/2018/09/30/politica/1538270819_523141.html. Acesso em: 28 fev. 2020.

LEPORE, Jill. The secret history of Wonder Woman. New York: Alfred A. Knopf, 2014. 
LIMA, Savio Queiroz. Vestígios e práticas de discursos feministas nos quadrinhos da Mulher-Maravilha: as ocultas mulheres de Bana-Mighdall. 2017. Dissertação (Mestrado em História) - Universidade Salgado de Oliveira, Niterói, 2017.

MAIGRET, Éric, Strange grew up with me: sentimentality and masculinity in readers of superhero comics. Réseaux, The French journal of communication, $v$. 7, n. 1, p. 05-27, 1999.

MCCLOUD, Scott. Raising readers. In: MCCLOUD, Scott (org.). The best America comics 2014. Boston: Houghton Mifflin Harcourt, 2014. p. 75-77.

MESSIAS, Carolina Ito. Um panorama da produção feminina de quadrinhos publicados na internet no Brasil. 2018. Dissertação (Mestrado em Comunicação Social) - Universidade de São Paulo, São Paulo, 2018.

MILLER, Ann; BEATY, Bart (orgs.). The french comics theory reader. Leuven: Leuven University Press, 2014.

MITCHELL, William John Thomas. Comics and media: afterwords. Critical inquiry, [Chicago], n. 40, p. 255-265, mar./jun. 2014.

MOULY, Françoise. Découpage. In: MOULY, Françoise (org.). The best America comics 2012. Boston: Houghton Mifflin Harcourt, 2012. p. XIII-XVII.

NÓBREGA FILHO, Emanoel. História das multiplicidades travestis em Muriel Total, de Laerte Coutinho: cartografias discursivas da estética de si por um devir transgênero. 2016. Tese (Doutorado em Letras) - Universidade Federal da Paraíba, João Pessoa, 2016.

NOGUEIRA, Natânia. As representações femininas nas histórias em quadrinhos norte-americanas: June Tarpé Mills e sua Miss Fury (1941-1952). 2015.

Dissertação (Mestrado em História) - Universidade Salgado de Oliveira, Niterói, 2015.

NYBERG, Amy. Seal of approval: a history of the comics code. Jackson: University Press of Mississipi, 1998.

OGI, Fusami et al. Women's manga in Asia and beyond: uniting different cultures and identities. Londres: Palgrave Macmillan, 2019.

OKSMAN, Tahneer. How come boys come to keep their noses: women and jewish american identity in contemporary graphic memoirs. New York: Columbia University Press, 2016. 
OLIVEIRA, Francine. Queer em quadrinhos: representações brasileiras contemporâneas. 2014. Dissertação (Mestrado em Letras) - Universidade Federal de São João del-Rei, São João del-Rei, 2014.

OLIVEIRA, Cláudio José. Sindicalismo, piratas e cabelo Chanel: leituras de reciclagem cultural em obras de Laerte. 2014. Tese (Doutorado em Letras) Universidade Federal da Bahia, Salvador, 2014.

PARSON, Sean; LEESON-SCHATZ, Joseph. (orgs.). Superheroes and masculinity: unmasking the gender performance of heroism. Lanham: Lexington Books, 2020.

PEREZ, Olívia; RICOLDI, Arlene. A quarta onda feminista: interseccional, digital e coletiva. In: CONGRESSO LATINO-AMERICANO DE CIÊNCIA POLITICA (ALACIP), 10., 2019. Monterrey. Anais [...]. Monterrey: ALACIP, 2019. Disponível em: https://alacip.org/cong19/25-perez-19.pdf. Acesso em: 20 jul. 2020.

PIRES, Maria Francisca da Conceição Pires. Outras mulheres, outras condutas: feminismos e humor gráfico nos quadrinhos produzidos por mulheres. ArtCultura, Uberlândia, v. 21, n. 39, p. 71-87, jul./dez. $2019 a$.

PIRES, Maria Francisca da Conceição Pires. Mulheres desregradas: autorretratos e o corpo grotesco nos cartuns de Chiquinha. Topoi, Rio de Janeiro, v. 20, n. 41, p. 302-316, maio/ago. 2019 b.

ROBBINS, Trina. The great women superheroes. Northampton: Kitchen Sink, 1997.

ROBBINS, Trina. Pretty in ink: north american women cartoonists, 1896-2013. Seattle: Fantagraphics, 2013.

ROBBINS, Trina. Babes in arms: women in comics during the Second World War. New Castle: Hermes Press, 2017.

SCOTT, Joan. História das mulheres. In: BURKE, Peter (org). A escrita da história: novas perspectivas. São Paulo: UNESP, 1992. v.1. p. 75-85.

SCOTT, Joan. Gênero: uma categoria útil de análise histórica. Educação e realidade, Porto Alegre, v. 20, n. 2, p. 71-99, 1995.

THEODORO, Hadriel. Transgeneridade, mídia e consumo: um estudo de caso das visibilidades midiáticas de Laerte Coutinho. 2016. Dissertação (Mestrado em Comunicação e Práticas de Consumo) - Escola Superior de Propaganda e Marketing, São Paulo, 2016. 
WHALEY, Deborah Elizabeth. Black women in sequence: re-inking comics, graphic novels and anime. Seattle e Londres: University of Washington Press, 2016.

WROBEL, Jasmin. História(s) redesenhada(s): visualizando analogias entre hoje e o passado - periferias urbanas, resistência negra e vozes femininas na obra de Marcelo D’Salete. Artcultura, Uberlândia, v. 21, n. 39, p. 99-116, jul./dez. 2019.

Universidade do Estado de Santa Catarina - UDESC

Programa de Pós-Graduação em História - PPGH

Revista Tempo e Argumento

Volume 12 - Número 31 - Ano 2020 tempoeargumento@gmail.com 